\title{
An Overview of Bioenergy with Carbon Capture and Storage Process as a Negative Emission Technology
}

Saeed Talei ${ }^{*}$ and Zahra Soleimani ${ }^{2}$

${ }^{1}$ Energy and Environment Research Center, Niro Research Institute (NRI), Tehran, Iran.

${ }^{2}$ Department of Chemistry and Petroleum Science, Shahid Beheshti University, Tehran, Iran.

\section{*Corresponding Author:

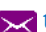 talei.saeed66@gmail.com}

Received: 15 Novemebr, 2020 Accepted: 05 January, 2021

Published: 30 January, 2021

\begin{abstract}
Projections of the pathways that reduce carbon emission to the levels consistent with limiting global average temperature increases to $1.5^{\circ} \mathrm{C}$ or $2^{\circ} \mathrm{C}$ above preindustrial levels often require negative emission technologies like bioenergy with carbon capture and storage (BECCS), it involves the conversion of biomass to energy, producing $\mathrm{CO}_{2}$ which is sequestered, transported and then permanently stored in a suitable geological formation. The potential of BECCS to remove $\mathrm{CO}_{2}$ from the atmosphere makes it an attractive approach to help achieving the ambitious global warming targets of COP 21. BECCS has a range of variables such as the type of biomass resource, the conversion technology, the $\mathrm{CO}_{2}$ capture process used and storage options. Each of the pathways to connect these options has its own environmental, economic and social impacts. This study gives an overview of Bioenergy with carbon capture and storage for the purpose of carbon mitigation while the challenges associated with using biomaterial was assessed, such as land use, water consumption and its economic constraints. The more certain way forward to underpin BECCS deployment, is to ensure that there is strong social support and integrated policy schemes that recognize, support and reward negative emission, for without negative emissions delivered through BECCS and perhaps other technologies, there is little prospect of the global targets agreed to at Paris, being met.
\end{abstract}

Keywords: Negative Emission, BECCS, CCS, Bio-energy, Climate Change

\section{Introduction}

There is considerable scientific evidence that the risk of irreversible and potentially catastrophic environmental changes, like unstoppable melting of polar land ice or Arctic tundra, will increase significantly if global warming reaches $2^{\circ} \mathrm{C}$ or more above the pre-industrial temperature, which is around $1.2^{\circ} \mathrm{C}$ above today's level. This global warming effect is ascribed to the increasing concentrations of $\mathrm{CO}_{2}$ and other greenhouse gases in the earth's atmosphere. It was calculated that, for example, emissions of $\mathrm{CO}_{2}$ may need to be reduced by more than $60 \%$ by 2100 , in order to stabilize the atmospheric concentration of $\mathrm{CO}_{2}$ at no more than $50 \%$ above its current level.

Fig 1 and 2, shows the upward trend of $\mathrm{CO}_{2}$ emission in the early years of the 21 st century. Fossil fuels are the dominant form of energy utilized in the world $(86 \%)$ and account for around $75 \%$ of the anthropogenic $\mathrm{CO}_{2}$ emissions $[1,2]$. 


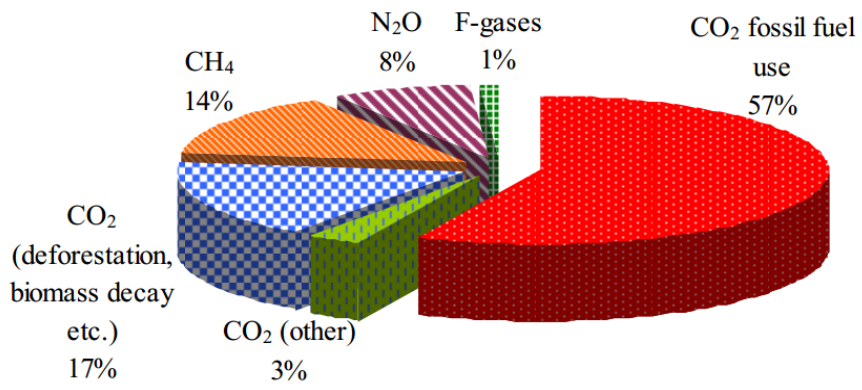

Figure 1. Share of different Greenhouse gases in total global emissions [1]

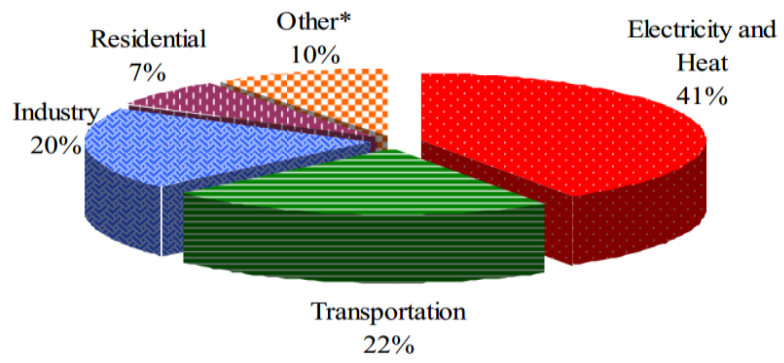

Figure 2. World $\mathrm{CO}_{2}$ emission by sector [2]

Electricity and heat generation and transportation are the sectors which produced two-thirds of global $\mathrm{CO}_{2}$ emissions in 2008 (Fig 2). Generation of electricity and heat (also known as public utilities) was by itself the main contributor to the $\mathrm{CO}_{2}$ emissions and responsible for $41 \%$ of the world $\mathrm{CO}_{2}$ emissions in 2008 . Worldwide, the electricity and heat sector relies heavily on coal, which is the most carbon-intensive fossil fuels. Countries such as Australia, China, India, Poland and South Africa produce between $69 \%$ and $94 \%$ of their electricity and heat through the combustion of coal. The future emissions intensity of the electricity and heat sector depends strongly on the fuel that will be used to generate the electricity and on the share of nonemitting sources from renewable sources and nuclear energy. By 2030, the World energy outlook (WEO) 2009 projects that demand for electricity will be almost twice as high as the current demand, driven by rapid growth in population and in income in the developing countries, by the continuing increase in the number of electrical devices used in homes and commercial buildings and by the growth in electrically driven industrial processes [1].

These trends underline the demand to develop technologies to reduce $\mathrm{CO}_{2}$ emission associated with the use of fossil fuels. Carbon dioxide Capture and Storage (CCS) offers this opportunity to reduce $\mathrm{CO}_{2}$ emission.

Regarding to the rising of $\mathrm{CO}_{2}$ concentration in the atmosphere Integrated Assessment Models (IAMs), which balance the economic and biophysical systems and their interaction, show that it is possible to limit global average temperature rises to $1.5-2^{\circ} \mathrm{C}$ via a combination of measures, including the extensive deployment of negative emissions technologies (NETs), primarily bioenergy with carbon capture and storage (BECCS) [3-6].

Interest in BECCS has grown rapidly as it has the potential to offer deep reductions in atmospheric $\mathrm{CO}_{2}$ concentrations. It also appears to be practicable and cost-effective. The IPCC Special Report on Renewable Energy Sources and Climate Change Mitigation addresses this in some detail [7]. It states that successful deployment of CCS in combination with biomass conversion could result in removals of greenhouse gases from the atmosphere at attractive mitigation cost levels. BECCS offers the potential to achieve long-term reductions in GHG emissions necessary to stabilize atmospheric $\mathrm{CO}_{2}$ concentrations, and could be applied to a wide range of biomass-related technologies [8].

It is predicted that given the technical limitations, around $30-60 \%$ of the $\mathrm{CO}_{2}$ emissions from electricity generation and $30-40 \%$ of those from industry (in total accounting for $20-40 \%$ of global fossil fuel $\mathrm{CO}_{2}$ emissions) are expected to be mitigated by CCS in the time period between 2010 and 2050 [9]. To reach the $2{ }^{\circ} \mathrm{C}$ scenario, $63 \%$ of coal-fired electricity generation $(630 \mathrm{GW})$ needs to be equipped with CCS by 2050 [10]. Although CCS is often associated with the use of fossil fuels, it can also be combined with the use of biomass, often referred to BECCS $[9,11]$. The share of biomass use in the energy system can exceed $27 \%$ in 2050 [7]. In the shorter term, Panoutsou et al. [12] and Hoefnagels et al. [13] estimated the potential share of biomass in Europe's energy system in 2020 to increase to $10.6 \%$ and $14.0 \%$, respectively. Considering this expected increasing share of biomass in the future energy system, BECCS offers an attractive potential for a net removal 
of carbon dioxide from the atmosphere, as is already highlighted by many studies [11,14-17]. Moreover, BECCS development could help to avoid the risk of reinforced fossil fuel lock-in which is associated with the implementation of CCS in conventional fossil fuel power plants $[18,19]$. In this paper, the history of CCS and BECCS will be reported so as to reach the general view about the current status of these technologies. Afterward, the ways we can use bioenergy to mitigate dire consequences of global warming is explained. Furthermore, the environmental and social impacts of BECCS will be reported.

\section{History of CCS}

It is necessary to give a brief overview of the history of Carbon Capture and Storage (CCS) before focusing on the concept of BECCS. CCS is widely regarded as an essential technology if the world is going to meet the targets specified in the 2015 Paris Agreement [20]. Since the advent of $\mathrm{CO}_{2}$ emissions being recognized as one of the primary drivers of global warming, there have been ideas of discounting the future costs of climate change through methods of climate mitigation, CCS being one of these methods. Since the idea of CCS via permanent underground storage was explored in 1976-1977, the concept has been utilized as a tool for mitigation. Especially when fossil fuel emissions became a prominent political concern during the 1990s [21]. With the advent of a $\mathrm{CO}_{2}$ emissions tax imposed in Norway on off-shore industrial installations, it became economically attractive to have a method of CCS in place for energy companies such as Statoil [21]. Since then, there have been a handful of large-scale demonstration projects of CCS that have continued to capture and inject over a million tonnes of $\mathrm{CO}_{2}$ per year [21].

There are different types of $\mathrm{CO}_{2}$ capture systems: post combustion, pre-combustion and oxy-fuel combustion (Fig. 3). The concentration of $\mathrm{CO}_{2}$ in the gas stream, the pressure of the gas stream and the fuel type (solid or gas) are important factors in selecting the capture system.

Post-combustion capture of $\mathrm{CO}_{2}$ in power plants is economically feasible under specific conditions [22]. It is used to capture $\mathrm{CO}_{2}$ from part of the flue gases from a number of existing power plants. Separation of $\mathrm{CO}_{2}$ in the natural gas processing industry, which uses similar technology, operates in a mature market [19]. The technology required for pre-combustion capture is widely applied in fertilizer manufacturing and in hydrogen production. Although the initial fuel conversion steps of pre-combustion are more elaborate and costly, the higher concentrations of $\mathrm{CO}_{2}$ in the gas stream and the higher pressure make the separation easier. Oxy-fuel combustion is in the demonstration phase [22] and uses high purity oxygen. This results in high $\mathrm{CO}_{2}$ concentrations in the gas stream and, hence, in easier separation of $\mathrm{CO}_{2}$ and in increased energy requirements in the separation of oxygen from air.

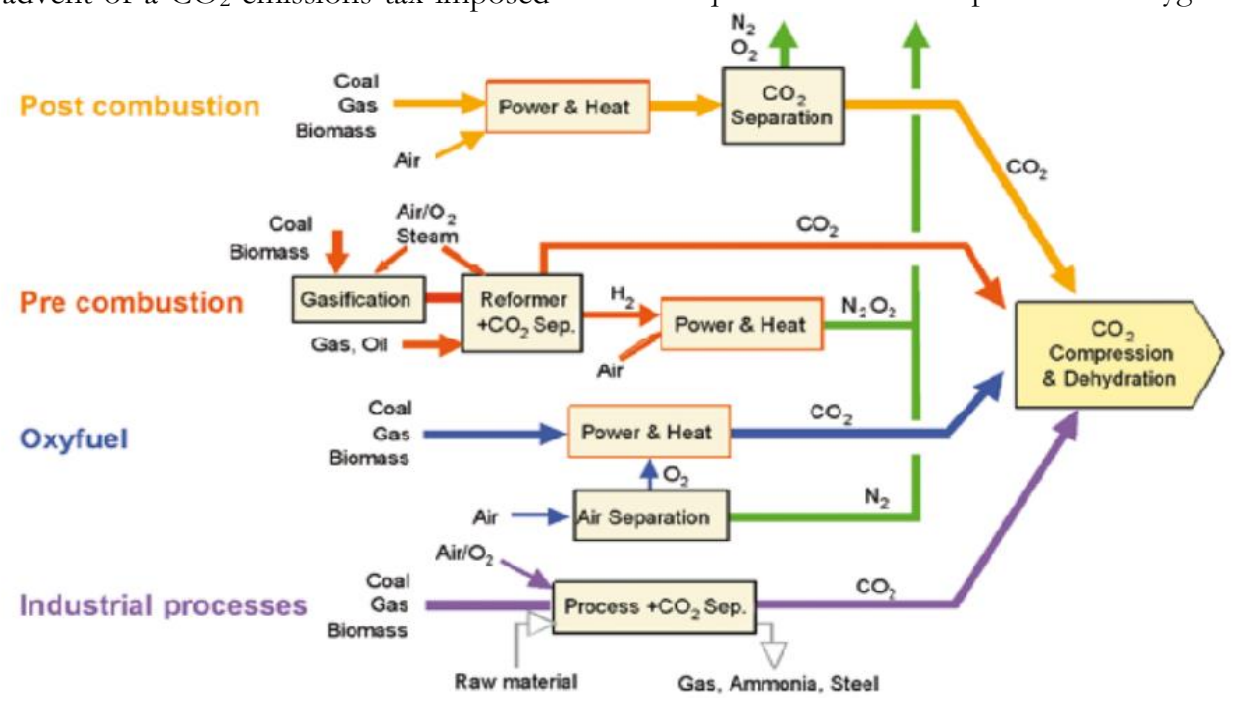

Figure 3. Schematic representation of capture systems [23]

CCS is a popular option in IAM mitigation portfolios as it can be integrated into pre-existing systems without the necessity of large-scale and costly amendments to the system [24]. BECCS has the "double benefit of mitigating emissions and generating energy, making it attractive from the cost-optimization perspective of an IAM." [24]. Despite the popularity of CCS (and specifically BECCS) in IAM decarbonisation rization scenarios, its current rate of deployment has not come close to reaching the levels that are indicated by the projections of the IAMs and decarbonisation roadmaps with CCS only appearing within a smattering of the NDCs pledged at COP21. A recent model intercomparison project, to which eighteen IAMs were contributed, found that the use of CCS, although varying widely from model-to-model, projected at least 
$600 \mathrm{Gt}$ (range of $600 \mathrm{Gt}-3050 \mathrm{Gt}$ ) of $\mathrm{CO}_{2}$ being captured and stored by 2100 (ibid). This amount is more than half than the required emissions reductions that are consistent with a $2^{\circ} \mathrm{C}$ pathway. This sheds light on the importance of CCS and the magnitude of its role in decarbonisation pathways. Research continues into CCS and how to make it more efficient and costeffective, especially in relation to the storage of the compressed $\mathrm{CO}_{2}$. CCS can also be used as an option in existing fossil fuel power plants [20].

\section{History of BECCS}

BECCS started as an idea from Kenneth Möllersten, a Swedish PhD student that considered finding financial benefits for the Swedish paper industry from the carbon market after the introduction of the Kyoto Protocol [25].This was taken up further by Möllersten and his $\mathrm{PhD}$ supervisors Jinyue $\mathrm{Yan}$ and Mats Westermark [26]. Möllersten later went on to work with his now colleague Obersteiner, the two scientists that were involved in the early stages of BECCS development [25]. This duo, along with a collection of other scientists, were quick to develop the idea after coming to the realization that there was the possibility of obtaining double the amount of carbon credits for avoided emissions at a pulp and paper mill using the technique of CCS. In their 2001 paper titled 'Managing Climate Risk', they made reference to BECCS [then classified as purely BECS] on eleven occasions [26]. By utilizing this new technological innovation as a tool to fix the ongoing climate change 'dilemma', the authors described the possible incorporation of BECCS into an extensive risk management scheme that focused on mitigation. Within the paper, the largest limitations recognized for BECCS are the projected high costs of installation with a single mention given to the required research needed in order to figure out how to use BECCS as a sustainable technology in a 'wider sense' [26].

Obersteiner claims [25] that, as the self-proclaimed founder of BECCS as a tool to allow for ambitious climate targets, that the use of the NET in a risk management scheme was misinterpreted and consequently misused in emission pathway scenarios within global climate governance. He criticizes IAMs for being deterministic and for not allowing room for critical risk management thinking [25]. Much like Kevin Anderson, one of the critics of BECCS' large-scale implementation [27], he states that BECCS should be used as a backstop technology that can be potentially used to deal with sudden climate feedbacks and abrupt shocks to the system, he reiterates that plans for conventional methods of climate mitigation should be made with BECCS to be used only as an optional backstop if required [25].

BECCS consists of multiple components and stages: biomass feedstock and collection, conversion of the biomass feedstock into energy, production of heat, electricity, or fuels, and capture and sequestration of the carbon resulting from using that energy (see Table 1). A number of biomass sources and potential feedstocks were addressed in Table 1, including woody biomass, corn grain, agricultural residues, waste biomass, and energy crops. The discussions focused on thermochemical approaches for energy conversion, including combustion, pyrolysis, and gasification, also the uses of this energy was discussed for heat and electricity applications and the production of liquid fuels. Geologic storage is used to sequestrate $\mathrm{CO}_{2}$ captured in this technology. Moreover, it was noted that biological carbon sequestration can be achieved by applying biochar, a byproduct of pyrolysis, to soils [19].

Table 1

Components of BECCS [18].

\begin{tabular}{|c|c|c|c|}
\hline Potential Biomass Feedstocks & Conversion Pathway & Energy & Sequestration \\
\hline Woody biomass, such as & Combustion, in which & Heat & Geologic storage \\
\hline -harvested wood products & the biomass is oxidized & & such as \\
\hline -harvest residue(from wood used for & completely for power & Electricity & -saline aquifers \\
\hline other purposes) & and/or heat production & & -depleted hydrocarbon \\
\hline & & Liquid fuels & reservoirs \\
\hline Corn grain & Pyrolysis, in which & such as & \\
\hline & biomass is heated in & -ethanol & Biochar \\
\hline $\begin{array}{l}\text { Waste biomass } \\
\text {-municipal solid waste } \\
\text {-manure }\end{array}$ & $\begin{array}{l}\text { the absence of oxygen, } \\
\text { producing liquids and/ } \\
\text { or biochar }\end{array}$ & $\begin{array}{l}\text {-biodiesel } \\
\text {-long chain } \\
\text { hydrocarbons }\end{array}$ & $\begin{array}{l}\text { which can be used as a soil } \\
\text { amendment }\end{array}$ \\
\hline
\end{tabular}

Agricultural residues, such as -corn stover

Energy crops, such as -Switchgrass

-Miscanthus
Gasification, in which biomass is partially oxidized under oxygen starved conditions for the production of syngas 


\section{Biofuel production and BECCS}

As with some industrial processes, carbon dioxide can be captured during certain stages of the production of biofuels. These stages usually emit concentrated carbon dioxide with no further need for separation or the separation stage is already a part of the process.

\section{Bioethanol}

Bioethanol is the most common biofuel, accounting for more than $80 \%$ of total biofuel use worldwide [28]. Bioethanol is produced by fermenting sugar or starch. The ethanol is then in the next step distilled to fuel grade ethanol. The feedstock includes all sugar and starch containing biomass such as cereal crops, maize, sugarcanes, sugar beets, potatoes, sorghum and cassava. There are also technologies available for ethanol production from lignocellulosic biomass although this requires advanced pretreatment processes.

Capture of carbon dioxide from bioethanol can both be done as a part of the fermentation process and from the flue gases of the boiler for the production of heat and power. The fermentation step of both conventional and advanced bioethanol production is similar resulting in the same amount of carbon dioxide with a concentration of about 98.8-99.6\% after dehydration [28].The carbon dioxide stream then has atmospheric pressure and a temperature between 25 and $50^{\circ} \mathrm{C}$ and further treatment is not necessary. The carbon dioxide captured from the flue gases of the boiler are in a comparable amount to that from the fermentation, although the carbon dioxide concentration is considerably lower and therefore also requires an additional separation step.

\section{Biodiesel}

Biodiesel is mainly produced by transesterification of vegetable oil but synthetic biodiesel could also be produced based on gasification. The biomass feedstock is gasified into mainly hydrogen, carbon monoxide and carbon dioxide and then recombined into liquid fuel by the Fischer-Tropsch reaction producing more carbon dioxide. The product generated by the reaction has to be upgraded using conventional techniques like hydrocracking.

Removal of the carbon dioxide is already an important step of the cleaning of the synthesis gas before it can be processed. Pre-combustion technology is used in the same way as the capture of carbon dioxide previously described for gasification [28].

\section{Biomethane}

Biogas is methane rich gas produced by anaerobic digestion of biomass, usually organic waste. Biogas can either be burnt for power generation or heating purposes or upgraded to natural gas standard. The upgrading process releases carbon dioxide and the end product is known as Biomethane. Biomethane is upgraded from biogas by separating carbon dioxide and removing sulfurous components.

Even though the separation process is commercially proven and frequently used, it faces challenges for CCS purposes because of the relatively small amounts of carbon dioxide captured [29].

\section{BECCS potential to deliver negative emission}

A wide range of views on the negative emission potential of BECCS can be found in the literature, ranging from $1000 \mathrm{EJ} /$ year to $100 \mathrm{EJ} /$ year and with a $\mathrm{CO}_{2}$ removal capacity of $0-20 \mathrm{Gt} \mathrm{CO}_{2} /$ year [30]. The majority of IAM models have considered BECCS in the portfolio of essential mitigation technologies, with a removal potential of 2-10 $\mathrm{Gt} \mathrm{CO}_{2} /$ year [31]. This value is comparable with the $\mathrm{CO}_{2}$ removed by the natural carbon cycle, such the ocean $\left(9.2 \pm 1.8 \mathrm{Gt} \mathrm{CO}_{2}\right)$ and terrestrial carbon sinks $\left(10.3 \pm 2.9 \mathrm{Gt} \mathrm{CO}_{2}\right)$ [31].

According to Gasser et al. [32], a "best-case" to achieve the RCP 2.6 target in addition to conventional mitigation would require BECCS with annual negative emissions of $1.8-11 \mathrm{Gt} \mathrm{CO}_{2}$. In recent IEA global models, BECCS could potentially deliver negative 14 Gt $\mathrm{CO}_{2}$ between 2015-2050, which $11 \mathrm{Gt} \mathrm{CO}_{2}$ is captured from biofuels with CCS and $3 \mathrm{Gt} \mathrm{CO}_{2}$ from dedicated and co-firing BECCS for power [33]. A review study by Kemper [34] found the global technical potential of BECCS, through biomass gasification and direct combustion, to be around $10 \mathrm{Gt} \mathrm{CO}_{2} /$ year in 2050. Woolf et al. [35] estimated a lower global net negative emission of 3.3-7.5 Gt $\mathrm{CO}_{2} /$ year. Ricci and Selosse [36] used the multiregional TIAM-FR optimization model to assess the global and regional potential of BECCS. Their study showed that by 2050 , BECCS and CCS could generate $23 \%$ to $30 \%$ of total global electricity, equivalent to 5.7-7.6 Gt $\mathrm{CO}_{2}$ captured and stored. Most of this projected capacity lies in developing countries, especially China, India and Brazil.

In a complementary study, Ricci and Selosse showed that a near-term widespread adoption of CCS with $15 \%$ BECCS, would be the preferable pathway to achieving stringent emission targets [37]. In a study by Koornneef, et al. [38], the economic potential of BECCS would be up to $3.5 \mathrm{Gt} \mathrm{CO}_{2} /$ year negative emissions from the power sector and $3.1 \mathrm{Gt} \mathrm{CO}_{2}$ /year in transportation. However, these potentials are not for the whole sectors but for the "best" routes, i.e. BIGCC-CCS and FT biodiesel in 2050. An assessment of the assumptions underpinning the feasibility of BECCS in IAM scenarios by Vaughan and Gough [39] showed that assumptions regarding technical aspects of BECCS are realistic. However, their results warned that 
the socio-political assumptions and projections of the future large-scale deployment of bioenergy are unrealistic [39].

The fig 4 below depicts the general process of BECCS; outputs of BECCS include power and heat, pulp and paper, and biofuels. The capture and storage can be done pre-combustion, during the combustion (oxyfuel), and post combustion.

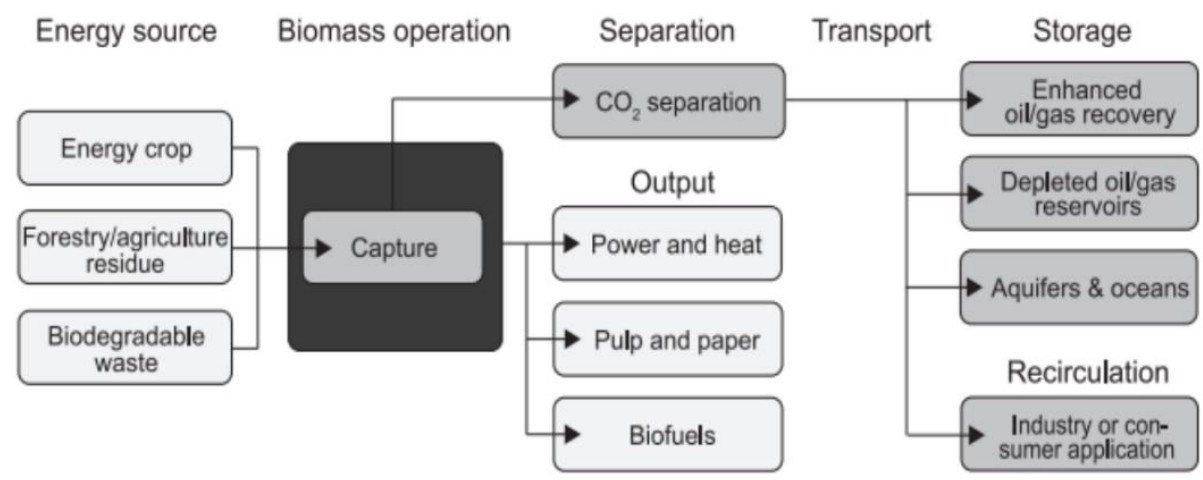

Figure 4. General process of BECCS [39]

\section{Economic implications of BECCS}

One of the important parameters, which constrains achieving the potential for removing $\mathrm{CO}_{2}$ of the NETs is their economic performance. With no large-scale NET project, estimation of their cost merely relies on hypothetical situations in the future. Most studies agree that among three NETs with highest technical potential (namely BECCS, direct air capture (DAC) and afforestation \& reforestation (AR)), DAC with up to $\$ 400-\$ 600 / \mathrm{tCO}_{2}$ is the most costly option and BECC with $\$ 150-\$ 250 / \mathrm{tCO}_{2}$ and $\mathrm{AR}$ with $\$ 10-\$ 65 / \mathrm{tCO}_{2}$ have a lower cost [40-43]. The scope of this study is limited to power generation BECCS options, but it is worth mentioning that a lower value of BECCS cost could be achieved at bioethanol refinery with less than $\$ 25 / \mathrm{tCO}_{2}$ [44].

The high cost of these NETs, highlights the necessity of an effective mitigation mechanism such as carbon price. According to McGlashan [41] an effective carbon price in their definition should be more than to mitigation cost of the cheapest large-scale NET option. McLaren [42] foresaw that the suitable technical and economic prerequisites for NETs deployment at the level of 10-20 Gt $\mathrm{CO}_{2}$ per year could become obtainable by 2030-2050. According to McGlashan et al. [41] the cost of a large BECCS power plant is $\$ 59$ $111 / \mathrm{tCO}_{2}$. In a study by McLaren [41] a range of $\$ 70$ $\$ 250 / \mathrm{tCO}_{2}$ is suggested for BECCS [42]. This study indicated that in the absence of rapid development, the cost of BECCS is more likely to be $\$ 150 / \mathrm{tCO}_{2}$ [42].

Although the future technical potential of BECCS is estimated to be considerable, not all of it will be economically viable. One of the major contributions of BECCS would be in the power generation sector. The current electricity market is deeply dependent on fossil fuels and there is no united price for $\mathrm{CO}_{2}$ emission. As a result, the high production cost of BECCS, considering its high investment and O\&M costs, would not be competitive in the power market. Based on a review by Kemper [34], the levelized cost of electricity production (LCOE) through BECCS lies between $\$ 70$ $\$ 230 /$ MWh.

\section{Environmental impacts of BECCS}

There is great deal of uncertainty regarding the possible environmental impacts of large-scale NETs. The major impacts found in the literature are land use change, water use, energy input, effect on albedo and natural carbon cycle [40,45-48].

Sustainability of biomass feedstock production is one of the main sources of uncertainty in estimating the global technical potential of BECCS. Climate dynamics, economic and technological development, human population growth (and its effect and demand for food, fodder and fuel) and natural carbon cycle are some of critical uncertainties influencing the future potential of BECCS [30, 49-53].

Historically, unsustainable biomass harvest and forest clearing in some areas, has led to loss of a considerable proportion of natural forests and degradation of productive lands [46, 50], increased GHG emissions, loss of biodiversity and carbon stock [54-60] and depletion of water resources [54-56, 61]. Intensification of energy crops production could result in severe competition between food, feed, and energy feedstock supplies, leading to controversial economic, ethical, and environmental issues [30,62].

If strategies for large-scale BECCS deployment do not meet strict sustainability criteria, its negative externalities could be very problematic. Therefore, expanding bioenergy production must be carefully 
considered against the background of sustainability [53].

\section{Land-use}

Increasing demand for biomass and limited arable lands may cause expansion of agricultural lands, loss of natural forests and ecological reserves. Land-use change includes; direct (LUC)-where the land encroaches on neighbouring forests or reserves, or indirect (iLUC) where the land previously cultivated for food production is used for energy crops and some other natural forests is substituted for food agriculture [63-65].

Unsustainable expansion of bioenergy production will exacerbate the GHG emissions from agricultural and forestry systems. Emissions from agriculture, forestry and other land-use change (AFLOU) account for approximately 10 to $12 \mathrm{Gt} \mathrm{CO}_{2}$ /year of anthropogenic GHG emissions; with 5-5.8 Gt $\mathrm{CO}_{2} /$ year from agricultural production and 4.3-5.5 $\mathrm{Gt} \mathrm{CO}_{2}$ /year from land use and land-use change activities [50]. According to Le Quéré et al. [66] emissions related to land-use change represent about $9 \%$ of the total emissions in the last decade. These emissions were principally associated with deforestation and expanding agricultural land use. GHG emission in agriculture is due to land-use change, fertilizers, livestock and fossil fuel machinery used. With present practices, the agriculture sector is one of the major contributors to global warming. Agricultural activities account for approximately $58 \%$ of the total $\mathrm{N}_{2} \mathrm{O}$ and $47 \%$ of the total $\mathrm{CH}_{4}$ emission [62].

Net forest emission is the difference between GHG emissions gained and emitted from forest land. $\mathrm{CO}_{2}$ emission lost is due to oxidization of carbon stock in biomass as a result of conversion of forest land to pasture or agricultural land. $\mathrm{CO}_{2}$ gained occurs by fixation of carbon through increasing the forest land. The net emission from forest land conversion in 2011 was $3.74 \mathrm{Gt} \mathrm{CO}_{2}$ which was almost $70 \%$ of the emission from the agricultural sector. Burning forest is another source of $\mathrm{CH}_{4}$ and $\mathrm{N}_{2} \mathrm{O}$ emission from combustion of biomass and organic soil. In 2011 the total GHG emissions from burning forests was $290 \mathrm{Mt}$ $\mathrm{CO}_{2}[67]$.

Tubiello et al. [68] found that land-use emissions have remained stable at about $4.8 \mathrm{Gt} \mathrm{CO}_{2} /$ year, whereas emissions from agriculture has kept growing by approximately $1 \%$, to $5.4 \mathrm{Gt} \mathrm{CO}_{2} /$ year.

\section{Water consumption}

Total withdrawal of freshwater from aquifers, streams and lakes by humans is around $3,853 \mathrm{~km}^{3} /$ year [69]. Around $70 \%$ of this amount is used for agriculture and in some fast-growing economies this percentages is up to $90 \%[69,70]$. To obtain the potential of BECCS at scale, a considerable proportion of the available water resources might need to be dedicated to biomass production. Although there are some plants that grow with low water consumption and high resistance to drought, in most regions biomass production could take a significant share of the available fresh water [61]. In particular, expansion of bioenergy from energy crops may intensify pressure on water resources [34]. One of the expected impacts of climate change is changing the precipitation patterns, loss in soil moisture and water scarcity [71].

That will be especially a challenge in regions like subSaharan Africa, Middle East and western America, Mexico and Australia, which are already facing a water scarcity [54,56, 71]. According to Creutzig et al. [72], water scarcity in areas such as Middle East, parts of Asia and western USA reduce the technical potential of bioenergy by $17 \%$ by mid-century.

Fajardy et al. [51] estimated that in order to deliver around $12.1 \mathrm{Gt} \mathrm{CO}_{2}$ /year, between 3.6 and $15.7 \mathrm{Tm} 3$ water will be required. Smith .et al. [40] found that the water needed to deliver the same negative emission through BECCS in 2100 would be approximately 720 $\mathrm{km} 3$.

A portion of the water consumption associated with BECCS is due to the CCS process. For instance, the water used for cooling in a MEA-based $\mathrm{CO}_{2}$ capture unit is around $106 \mathrm{~m} 3 / \mathrm{t} \mathrm{CO}_{2}$ [73].

Water contamination is another ecological concern. Using fertilizers and pesticides for biomass production could be a source of water pollution. In addition, $\mathrm{CO}_{2}$ leakage and its subsequent environmental impacts on acidification of underground water is the major concern for geological storage [55,61].

\section{Efficient biomass production methods}

To meet the degree of biomass production needed for food and bioenergy demand and bearing in mind the limited natural resources and probable adverse impacts of climate change, a fundamental enhancement of the agriculture system seems essential. One way to do this would be to increase the efficiency without increasing environmental damage [71], which could potentially reduce emissions from this sector by $770 \mathrm{Mt} \mathrm{CO}_{2} /$ year by 2030 [74].

Several options to increase the efficiency of agricultural production while mitigating its correspondent emissions have been proposed. The green economy and climate-smart agriculture are two of the main concepts contributing to this goal. Green economy "combines the concepts of economic efficiency and production efficiency in agriculture given the increasing scarcity of the natural resources" [71,75]. Climate-smart agriculture (CSA) is a way to adapt agricultural practices under climate change in order to assure secure crop production $[67,71,76]$. Conservation agriculture (CA) is a CSA method which promotes practices to improve the mitigation and adaptation of agriculture to climate change through minimal mechanical soil disturbance 
(i.e. no tillage and direct seeding), crop rotation, restoring soil cover and bio-control of pest and weed [76-78].

Sustainable crop production intensification (SCPI) [71] is another method which employs efficient and smart use of crops, water and nutrients. One example is planting legume crops which helps to biologically fix the nitrogen in soil [71, 79]. This method increases production, improves the annual yield and reduces $\mathrm{N}_{2} \mathrm{O}$ emission [71, 79].

\section{Social impact of BECCS}

One of the main challenges of expanding bioenergy from dedicated energy crop is to maintain food security and affordability. Land-use change and its likely impacts on social equity and land ownership is another challenge of bioenergy.

The current food production system is very inefficient. According to McKenzie and Williams [80] around 40\% of the food produced is lost throughout its production to consumption. With current food production system, 32 countries are facing food crisis, with approximately 870 million people estimated to be undernourished and 1 billion malnourished [71]. Despite the current inefficiencies to cover food demand the food production has to grow by $60 \%$ to feed around 9 billion people in 2050 [52, 74, 81,82]. Reducing food loss and change in diet are most likely to change the demand for food by $30-50 \%$ [83, 84]. However, in the absence of required advancements in food production and in light of limited land and water resources, this put even more constraints on expanding lands for energy crop cultivation; especially when energy crops substitute food crops or food crops are used for bioenergy production.

The impact of this change will be more severe in developing and underdeveloped countries where price of food constitutes a higher share of the income. A study by Popp et al. [85] showed that large-scale bioenergy deployment (up to 300 EJ from energy crops) could potentially increase the food price by $82 \%$ in Africa, $73 \%$ in Latin America and $52 \%$ in Asia Pacific by the end of century. This could be a source of inequity in access to food across the globe. This effect has already been observed in 2007-2008, when alongside other factors high bioethanol demand in fuel market in North America led to sharp increase in food price followed by food riots in many developing countries [86].

According to the IPCC AR5 [3] around 100 EJ/year can be supplied from agricultural and forestry residues, dung and organic waste. Lotze-Campen et al. [87] showed that deployment of this bioenergy will most likely increase the food price by $5 \%$, whereas the direct effect of climate change on food price will be around $25 \%$. A study by Muratori et al. [88] confirmed that inclusion of BECCS in portfolio of mitigation technologies in a 2SD scenario would lessen the demand for biomass and thus the subsequent impact on food price.

Ferroukhi et al. [89] showed that bioenergy "as long as it is sustainably produced and managed" can offer social benefits to rural area by improving energy and food security and poverty alleviation through creating new market for biomass and wastes and also job creation.

\section{Conclusion}

The ultimate goal of the agreement achieved at the UN climate conference in Paris in 2015 is to hold "the increase in the global average temperature to well below $2{ }^{\circ} \mathrm{C}$ and to pursue efforts to limit the temperature increase to $1.5^{\circ} \mathrm{C}$ above preindustrial level" A majority of the scenarios in the UN FCCC database designed to achieve, such as outcome requires negative emission technologies. However, it seems that for the BECCS technology logistics and land use constraints will limit BECCS to less than what is needed.

As discussed in this paper, the main uncertainties weighing on BECCS development are bioenergy availability, CCS development, policy incentives and social acceptance. Bioenergy availability is subjected to many uncertainties such as the rate of improvement in agricultural management, choice of crops and their yields, changes in food demands and human diets, use of degraded land, competition for water, use of agricultural/forestry by-products, protected area expansion, water use efficiency, climate change impacts, carbon neutrality of the biomass.

The major barrier for commercial deployment of BECCS is the lack of economic, social and political incentive, rather than technical (assuming fossil-fuel CCS is now a proven technology). The potential role of BECCS for captureing atmospheric $\mathrm{CO}_{2}$ is unique as it will provide high capacity. To enhance the economic viability and encourage deployment of BECCS plant with higher $\mathrm{CO}_{2}$ negativity, financial incentives for reduction of $\mathrm{CO}_{2}$ emissions would be necessary. To improve the commercial potential of BECCS, there is aneed to develop sustainable biomass supply chains and establish suitable $\mathrm{CO}_{2}$ sequestration sites.

\section{References}

1. Solomon, Susan. IPCC. Climate change the physical science basis. 2007; AGU Fall Meeting Abstracts.

2. Birol F. World energy outlook. Int Energ Agency, 2010; 1:3.

3. Edenhofer O, Pichs-Madruga et al. Technical summary. Climate Change 2014: Mitigation of Climate Change Contribution of Working Group III to the 
Fifth Assessment Report of the Intergovernmental Panel on Climate Change. Cambridge University Press, Cambridge/New York, 2014; 31-72.

4. Peters GP, Andrew RM et al. The challenge to keep global warming below $2{ }^{\circ} \mathrm{C}$. Nat Clim Change, 2013; 3: 4-6.

5. Fajardy M, Mac Dowell N. Can BECCS deliver sustainable and resource efficient negative emissions? Energ Environ Sci. 2017; 10: 1389-1426.

6. Fajardy M, Mac Dowell N. The energy return on investment of BECCS: is BECCS a threat to energy security? Energ Environ Sci. 2018; 11: 1581-1594.

7. IPCC. Special report on renewable energy sources and climate change mitigation, working group III mitigation of climate change, potsdam institute for climate impact. Research (PIK), Potsdam, Germany. 2011.

8. Global CCS Institute. Global Status of BECCS Projects, Karlsson H, Byström L, Biorecro AB. Stockholm, Sweden. 2010.

9. IPCC. Carbon capture and storage. Special Report of Intergovernmental Panel on Climate Change; 2005. 10. IEA. Energy technology perspectives 2012. Pathways to a Clean Energy System. Int Energ Agency, 2012.

11. Azar C, Lindgren K, Obernsteiner M, Riahi K, van Vuuren D, den Elezen M, et al. The feasibility of low CO2 concentration targets and the role of bioenergy carbon-capture and storage. Clim Change, 2010; 100: 195-202.

12. Hoefnagels R, Junginger M, Resch G, Matzenberger J, Panze C, Pelkmans L. Development of a tool to model European biomass trade. Report for IEA. Bioenergy Task 40; November 2011.

13. ZEP. Biomass with CO2 capture and storage (Bio-CCS): The way forward for Europe; 2012. ZEP.

14. IEAGHG. Potential for biomass and carbon dioxide capture and storage; 2011.

15. Cough C, Upham P. Biomass energy with carbon capture and storage (BECCS or Bio-CCS). Greenhouse Gas Sci Technol. 2011; 1: 324-34.

16. Rhodes JS, Keith DW. Engineering economic analysis of biomass IGCC with carbon capture and storage. Biomass Bioenerg. 2005; 29: 440-450.

17. Obersteiner M, Azar C, Kauppi P. Managing climate risks. Sci. 2001; 294: 786-787.

18. Vergragt PJ, Markusson N, Karlsson H. Carbon capture and storage, bio-energy with carbon capture and storage, and the escape from the fossil-fuel lockin. Global Environ Chang. 2011; 21: 282-292.

19. NASEM (National Academies of Sciences, Engineering, and Medicine). 2018. Land Management Practices for Carbon Dioxide Removal and Reliable Sequestration: Proceedings of a Workshop-in Brief. Washington, DC: The National Academies Press.
20. Anthony E. Carbon capture and storage and carbon capture, utilisation and storage. Issu Environ Sci Technol. 2018; 45: 198-215.

21. Evar B, Armeni C, Scott V. 2012. An introduction to key developments and concepts in CCS. The social dynamics of carbon capture and storage: Understanding CCS representations, governance and innovation.

22. Ribeiro L. Present day conditions in the world of Carbon Capture and Storage (CCS) projects. Editors: Manchao He Luis Ribeiro e Sousa Derek Elsworth (2012).

23. Metz Bert et al. Carbon dioxide capture and storage. IPCC Special Report, 2005; 342.

24. Bui M, Adjiman C. et al. Carbon capture and storage (CCS): The way forward. Energ Environ Sci. 2018; 11(5), 1062-1176.

25. Hickman L. 2016. Timeline: How BECCS became climate change's 'saviour' technology | Carbon.

Brief.

26. Obersteiner M, Azar C, Kossmeier S, Mechler R, Moellersten K, Nilsson S, Read P, Yamagata Y, Yan J. 2001. Managing climate risk.

27. Anderson K, Peters G. The trouble with negative emissions. Sci. 2016; 354(6309): 182-183.

28. IEAGHG. 2011b. Potential for biomass and carbon capture and storage. International Energy Agency Greenhouse Gas R\&D Program.

29. EBTP. 2012. Biomass with CO2 Capture and Storage (Bio-CCS). European Biofuels Technology Platform.

30. Kemper J. Biomass with carbon capture and storage (BECCS/Bio-CCS), in IEA Greenhouse Gas R\&D Program. 2017, Imperial College London: London, UK.

31. Sabine Fuss JGC, Glen P. Peters, et al. Betting on negative emissions. Nat Clim Chang. 2014; 4.

32. Gasser T, Tachiiri CGK, Jones, CD, Ciais P. Negative emissions physically needed to keep global warming below 2 degree C. Nat Comm. 2015.

33. McCulloch S. 20 Years of carbon capture and storage-accelerating future deployment. 2016, International Energy Agency: Paris, France.

34. Kemper J. Biomass and carbon dioxide capture and storage: A review. Int J Greenhouse Gas Contr. 2015; 40: 401-430.

35. Dominic Woolf JEA, Alayne Street-Perrott F, Johannes Lehmann, Stephen Joseph. Sustainable biochar to mitigate global climate change. Nat Comm. 2010: 1 .

36. Olivia Ricci SS. Global and regional potential for bioelectricity with carbon capture and storage. Energ Pol. 2013: 52: 689-698.

37. Sandrine Selosse OR. Achieving negative emissions with BECCS (bioenergy with carbon capture and storage) in the power sector: New insights from the TIAM-FR (TIMES Integrated 
Assessment Model France) model. Energ. 2014; 76: 967-975.34.

38. Joris Koornneef PVB, Carlo Hamelinck et al. Global potential for biomass and carbon dioxide capture, transport and storage up to 2050. Int J Greenhouse Gas Contr. 2012; 11: 117-132.

39. Naomi E Vaughan CG. Expert assessment concludes negative emissions scenarios may not deliver. Environ Res Lett. 2016; 11.

40. Pete Smith SJD, Felix Creutzig et al. Biophysical and economic limits to negative $\mathrm{CO} 2$ emissions. Nat Clim Chang. 2016; 6: 42-50.

41. McGlashan NNS, Workman M, Caldecott B. Negative emissions technologies, in briefing paper. Grantham Institute for Climate Change. 2012; 8.

42. McLaren D. A comparative global assessment of potential negative emissions technologies. Proc Safe Environ Protect. 2012; 90: 489-500.

43. Bronson W, Griscom JA. et al. Natural climate solutions. PNAS, 2017; 114: 11645-11650.

44. Irlam L. Global cost of carbon capture and storage. Global CCS Institute. 2017.

45. Fuss SC, Kraxner F, Peters GP. et al. Research priorities for negative emissions. Environ Res Lett. 2016; 11.

46. Dooley SKAK. The risks of relying on tomorrow's 'negative emissions' to guide today's mitigation action. 2016; Stockholm Environment Institute-U.S. Center: Somerville, USA.

47. Jonas Anshelm AH. The last chance to save the planet? An analysis of the geoengineering advocacy discourse in the public debate. Environ Hum. 2014; 5: 101-123.

48. MartinWeih SH, Friderike Beyer, Petra Fransson. Traits to ecosystems: the ecological sustainability challenge when developing future energy crops. Frontiersin Energy Research | Bioenergy and Biofuels, 2014; 2.

49. Fridahl M. Socio-political prioritization of bioenergy with carbon capture and storage. Energ Pol. 2017; 104: 89-99.

50. Smith P, Bustamante M. Agriculture, Forestry and Other Land Use (AFOLU), in Climate Change 2014: Mitigation of Climate Change. 2014, IPCC: Berlin, Germany.

51. Mathilde Fajardy NMD. Can BECCS deliver sustainable and resource efficient negative emissions? Energ Environ Sci. 2017; 10: 1389-1426.

52. Walter Zegada-Lizarazu HWE, Salvatore L. Cosentino, Alessandro Zatta, Efi Alexopoulou, Andrea Monti. Agronomic aspects of future energy crops in Europe. Biofuels, Bioproducts and Biorefining, 2010; 4: 674-691.

53. Nasim Pour PAW, Peter J. Cook. A sustainability framework for bioenergy with carbon capture and storage (BECCS) technologies. Energy Procedia, 2017; 114: 6044-6056.
54. Powers SE. et al. Modeling water and soil quality environmental impacts associated with bioenergy crop production and biomass removal in the Midwest USA. Ecol Model. 2011; 222: 2430-2447.

55. Meyer MA, Priess JA. Indicators of bioenergyrelated certification schemes-An analysis of the quality and comprehensiveness for assessing local/regional environmental impacts. Biomass and Bioenergy, 2014; 65: 151-159.

56. Hennig C, Gawor M. Bioenergy production and use: Comparative analysis of the economic and environmental effects. Energ Conver Manag. 2012; 63: 130-137.

57. McBride AC. et al. Indicators to support environmental sustainability of bioenergy systems. Ecol Indicat. 2011; 11: 1277-1289.

58. Holland RA, Muggeridge FEA, Brown G, Clarke D, Taylor G. A synthesis of the eecosystem services impact of second generation bioenergy crop production. Renew Sustain Energ Rev. 2015; 46: 30-40.

59. Benefits and Costs of the Expanded Renewable Energy Target, D.o.C. Change, Editor. 2009, McLennan Magasanik Associates.

60. Colin Stucley SS, Ralph Sims, Jim Bland, Belinda Marino, Michael Borowitzka, Amir Abadi, John Bartle, Richard Giles, Quenten Thomas. Bioenergy in Australia; Status and Opportunities. 2012, Bioenergy Australia.

61. Fazio S, Monti A. Life cycle assessment of different bioenergy production systems including perennial and annual crops. Biomass and Bioenergy, 2011; 35: 4868-4878.

62. EU bioenergy potential from a resourceefficiency perspective. European Environment Agency: 2013; Luxembourg.

63. Ingeborg Kluts, Birka Wicke, Rik Leemans, André Faaij. Sustainability constraints in determining European bioenergy potential: A review of existing studies and steps forward. Renew Sustain Energ Rev. 2017; 69: 719-734.

64. Helena Chum AF, José Moreira. Bioenergy, in climate change mitigartion. 2011; IPCC.

65. Miyake S. et al. Land-use and environmental pressures resulting from current and future bioenergy crop expansion: A review. J Rural Stud. 2012; 28: 650658.

66. Le Quéré C, Andrew RM, Canadell JG, Sitch S, Korsbakken JI. et al. Global Carbon Budget 2015. Earth Syst Sci Data, 2015; 7: 349-396.

67. Tubiello MS. et al. Agriculture, forestry and other land use emissions by sources and removals by Sinks FS, Division, Editor. 2014, Food and Agriculture Organization of the United Nations (FAO).

68. Francescon T. et al. The contribution of agriculture, forestry and other land use activities to global warming, 1990-2012. Glob Chang Biol. 2015; 21: 2655-2660. 
69. AQUASTAT datasets. 2018, FAO.

70. Managing water under uncertainty and risk, in United Nations world water assessment program. 2012; UNESCO-WWAP.

71. Alexandre Meybeck VG. Climate smart agriculture- Sourcebook. 2013; FAO.

72. Creutzig F. et al. Bioenergy and climate change mitigation: an assessment. Glob Chang Biol Bioenerg. 2015; 7: 916-944.

73. Mohammad RM, Abu-Zahra LOHJS. et al. CO2 capture from power plants Part I. A parametric study of the technical performance based on monoethanolamine. Int J Greenhouse Gas Contr. 1; 3746.

74. Smith PJEO. Synergies between the mitigation of, and adaptation to climate change in agriculture. $J$ Agr Sci. 2010; 148: 543-552.

75. UNEP. Towards a green economy: pathways to sustainable development and poverty eradication. 2011; United Nations Environment Programme.

76. Leslie Lipper WM, Alexandre Meybeck et al. Climate-Smart agriculture policies, practices and financing for food security. Adapt Mitig. 2010; FAO: Rome, Italy.

77. Brendan H George IDN. Developing options for integrated food-energy systems-promising resources and systems for producing bioenergy feedstocks. IEA Bioenergy Task 43. 2012.

78. Brendan H George IDN. Supply chain logistics and economic considerations for short rotation woody crops in southern Australia. Developing Options for Integrated Food-Energy Systems 2012, IEA Bioenergy Task 43.

79. Wagner SC. Biological nitrogen fixation. Nat Educ Knowl. 2011; 3(10).
80. Fiona C McKenzie JW. Sustainable food production: constraints, challenges and choices by 2050. Food Secur. 2015.

81. World Population Clock. 2018, World Meter.

82. Bruinsma NAAJ. World agriculture towards 2030/2050. 2012, Food and Agriculture Organization of the United Nations (FAO): Rome, Italy.

83. Yvonne Y Deng MK, Martin Haigh, Veronika Dornburg. Country-level assessment of longterm global bioenergy potential. Biomass Bioenerg. 2015; 74: 253-267.

84. Helmut Haberl TB, Sribas C Bhattachary, KarlHeinz Erb, Monique Hoogwijk. The global technical potential of bio-energy in 2050 considering sustainability constraints. Curr Opin Environ Sustain. 2010; 2: 394-403.

85. Alexander Popp JPD. et al. The economic potential of bioenergy for climate change mitigation with special attention given to implications for the land system. Environ Res Lett. 2011; 6.

86. Wilkinson J. Biofuels and food security. Food Security and Nutrition. 2013, the High Level Panel of Experts: Rome, Italy.

87. Hermann Lotze-Campena MVL. et al. Impacts of increased bioenergy demand on global food markets: an AgMIP economic model inter comparison. Agr Econ. 2014; 45: 103-116.

88. Matteo Muratori KC, Marshall Wise, Page Kyle, Jae Edmonds. Global economic consequences of deploying bioenergy with carbon capture and storage (BECCS). Environ Res Lett. 2016; 11.

89. Rabia Ferroukhi DN, Alvaro Lopez-Peña et al. Renewable energy. Water Energ Food Nexus. 2015; The International Renewable Energy Agency (IRENA).

\section{ALKHAS}

Copyright: (C) 2020 The Author(s); This is an open-access article distributed under the terms of the Creative Commons Attribution License (http://creativecommons.org/licenses/by/4.0), which permits unrestricted use, distribution, and reproduction in any medium, provided the original work is properly cited.

Citation: Talei S, Soleimani Z. An Overview of Bioenergy with Carbon Capture and Storage Process as a Negative Emission Technology. ALKHAS. 2021; 3(1): 1-11.

https://doi.org/10.47176/alkhass.3.1.1 